\title{
Avaliação oficial: o que dizem os professores sobre o impacto na prática docente
}

\author{
Gisele Francisca da Silva Carvalho \\ Superintendência Regional de Ensino de São João Del-Rei \\ Maria do Socorro Alencar Nunes Macedo \\ Universidade Federal de São João Del-Rei
}

\section{Resumo}

Este artigo tem por objetivo discutir, a partir de indícios observados no discurso de professores alfabetizadores, o impacto que o Proalfa (Programa de Avaliação da Alfabetização do Estado de Minas Gerais) pode causar na prática docente. Foram utilizados como instrumentos de investigação a pesquisa documental, e, como instrumento central, realizamos dois encontros com um grupo focal formado por sete professoras alfabetizadoras. Como aporte teórico-metodológico, utilizaram-se conceitos como os de reforma e mudança, propostos por Popkewitz, táticas e estratégias, postulado por Certeau, além dos conceitos de polifonia e vozes, discurso de autoridade e internamente persuasivos, da teoria da enunciação de Bakhtin. Os resultados indicam que, diante das estratégias de governo, os professores lançam mão de táticas de consumo daquilo que é imposto às escolas como algo a ser seguido. As táticas variam de acordo com a legitimação conferida aos objetivos dessa política, ou seja, para que as professoras ajam de forma a corroborar o Proalfa, primeiro, elas têm que estar convencidas de que dará certo. Nos aspectos em que esse convencimento não se concretiza, elas colocam em prática as táticas de resistência, principalmente através de discursos marcados por elementos explicativos daquilo que não está sendo alcançado, bem como de suas possíveis causas.

\section{Palavras-chave}

Avaliação ofıcial - Discurso - Prática docente - Impacto.

\footnotetext{
Correspondência:

Gisele Francisca Da Silva Carvalho

Rua Antônio Floriano Da Silva, 63

36307-520 - São João Del-Rei / MG

E-mail: gi_francis@yahoo.com.br
} 


\title{
Official evaluation: what teachers say about its impact on teaching practice
}

\author{
Gisele Francisca da Silva Carvalho \\ Regional Education Superintendence of São João Del-Rei \\ Maria do Socorro Alencar Nunes Macedo \\ Federal University of São João Del-Rei
}

\begin{abstract}
The objective of this article is to discuss, based on evidences gathered from the discourse of literacy teachers, the impact that the Proalfa Program (Literacy Evaluation Program of the State of Minas Gerais) may have on their practice. The investigation instruments used were a documental research and, as a central tool, two meetings with a focus group comprised of seven literacy teachers. Theoretical-methodological support was drawn from concepts such as those of reform and change, as proposed by Popkewitz, tactics and strategies, postulated by Certeau, and also the concepts of polyphony and voices, authority discourse and internally persuasive, from Bakhtin's enunciation theory. Results indicate that, faced with government strategies, teachers resort to tactics of consumerism of what is imposed to schools as something to be followed. The tactics employed vary according with the legitimacy attributed to the objectives of the policy, that is to say, in order to have teachers act in such a way as to contribute to the Proalfa, they first have to be convinced that it will work. In the aspects where this persuasion fails to occur, teachers put in practice resistance tactics, mainly through discourses characterized by elements explaining what is not being achieved, as well as the possible causes for it.
\end{abstract}

\section{Keywords}

Official evaluation - Discourse - Teacher practice - Impact.

Contact:

Gisele Francisca Da Silva Carvalho

Rua Antônio Floriano Da Silva, 63

36307-520 - São João Del-Rei /MG

E-mail:gi_francis@yahoo.com.br 


\section{Introdução}

Este artigo tem por objetivo discutir, a partir de indícios observados no discurso de professores alfabetizadores, o impacto que o Proalfa (Programa de Avaliação da Alfabetização do Estado de Minas Gerais) pode causar na prática docente. Foram utilizados como instrumentos de investigação a pesquisa documental, e, como instrumento central, realizamos dois encontros com um grupo focal formado por sete professoras alfabetizadoras de cinco escolas estaduais da cidade de São João Del-Rei, na qual fica localizada a Superintendência Regional de Ensino (SRE). De acordo com Gatti (2005), o grupo focal é "uma técnica de levantamento de dados que se produz pela dinâmica interacional de um grupo de pessoas" (p. 12), podendo ser empregado "em processos de pesquisa social ou em processos de avaliação, especialmente nas avaliações de impacto" (p. 11).

Os documentos oficiais analisados foram decisivos na compreensão do Proalfa como proposta de avaliação e intervenção da alfabetização em Minas Gerais. Dentre eles destacam-se a matriz de referência do teste, os cadernos pedagógicos produzidos pelo Ceale (Centro de Alfabetização Leitura e Escrita) sob encomenda da Secretaria Estadual de Educação, o material Cantalelê (uma espécie de livro didático de alfabetização) e os resultados dos últimos anos do Proalfa. Devido aos limites deste texto, direcionaremos nossas análises para o discurso das professoras produzido nos dois grupos focais.

\section{Referências teórico-metodológicas}

Utilizamos como aporte teórico-metodológico conceitos como os de reforma e mudança, propostos por Popkewitz (1997), táticas e estratégias, postulado por Certeau (1994), além dos conceitos de polifonia e vozes, discurso de autoridade e internamente persuasivos, da teoria da enunciação de cunho bakhtiniano. Além disso, nos baseamos nos New Literacies Studies (STREET, 1984; HEATH, 1983), que vêm sendo divulgados há mais de uma década no Brasil e têm influenciado significativamente o campo das pesquisas em alfabetização e letramento.

Bakhtin 1995) postula que todo discurso é dialógico e polifônico, constituído de múltiplas vozes. De natureza heterogênea, o processo de produção de significados é contraditório, polissêmico e marcado pelo lugar social que os sujeitos ocupam no processo de enunciação, que, segundo Bakhtin, "é o produto da interação de dois indivíduos socialmente organizados" (1995, p. 112). Para o autor, o discurso comporta duas dimensões: uma de autoridade, outra de persuasão. 0 discurso de autoridade demanda que o reconheçamos, apropriando-o em bloco, sem questionamentos. Trata-se de um discurso já reconhecido no passado, localizado numa zona distante, hierarquicamente superior. 0 discurso internamente persuasivo é oposto ao discurso de autoridade e afirma-se pela apropriação do discurso do outro, transformando-o e povoando-o com nossas próprias palavras. 0 pressuposto de que o discurso comporta duas dimensões exclui qualquer possibilidade de uma interpretação dicotômica do discurso produzido pelos professores nos grupos focais por nós investigados.

Compreendemos a alfabetização na perspectiva do letramento como uma prática socialmente referenciada (SOARES, 2004). Tal concepção decorre dos estudos que compreendem o letramento como uma prática social marcada por relações de poder (BARTON; HAMILTON; IVANIC, 2000; HEATH, 1983; STREET, 1984). Soares (2004) propõe que haja um "reconhecimento da especificidade da alfabetização, entendida como processo de aquisição e apropriação do sistema de escrita, alfabético e ortográfico" e que a "alfabetização se desenvolva num contexto de letramento" (p. 16). 0 conceito de letramento como uma prática social é oposto à visão, ainda dominante, de letramento como um processo neutro e universal que reduz a escrita a uma técnica abstrata e desvinculada dos 
contextos em que circula. A essa visão, Street (1984) denominou "modelo autônomo de letramento”, em contraposição à visão ideológica de letramento defendida pelo autor.

A opção por utilizar o termo avaliação oficial não foi aleatória. Observamos que, na literatura sobre o tema, se tem utilizado nomenclaturas variadas, como avaliação em larga escala, avaliação externa, avaliação externa em larga escala, avaliação de rendimento escolar, avaliações dos sistemas de ensino, avaliação de monitoramento. Assim, optamos por sintetizá-los em um termo mais abrangente, no qual estivessem expressas todas essas características, chegando então ao conceito de avaliação oficial. Entendemos por avaliação oficial aquelas instituídas legalmente pelo poder público em âmbito nacional e estadual, com enfoque nos sistemas de ensino, elaboradas externamente às unidades escolares, aplicadas em larga escala e com datas previamente determinadas, cujos resultados são sistematizados e publicados por entidades específicas e, geralmente, tendo em vista subsidiar a elaboração de políticas públicas e intervenções pedagógicas. A avaliação oficial, para além desses aspectos, pode ser entendida como um dos dispositivos das propostas de reforma educacional:

Assim, a avaliação desempenha uma variedade de objetivos tais como: subsidiar o processo de ensino-aprendizagem; fornecer informações sobre os alunos, professores e escolas; atuar como respaldo para certificação e seleção bem como orientar na elaboração de políticas públicas e reformas educativas [...]. (CUNHA, 2005, p. 145)

No entanto, para a autora, "nessa lógica, a avaliação tornou-se um 'talismã', que fará milagres no aperfeiçoamento dos sistemas educativos" (CUNHA, 2005, p. 145). Isso sugere que é conferido a essas avaliações um poder redentor no que tange ao alcance da qualidade do ensino. 0 trato da reforma educacional como um "talismã" pode desencadear um entendimento equivocado do conceito de reforma, numa relação direta de causa e efeito na qual tendemos a pensar que a reforma educacional levará ao progresso da educação. Sobre a noção de reforma e progresso, Popkewitz (1997) pontua:

Nossa tendência é de associá-la ao progresso que vincula o conhecimento profissional com o melhoramento social. No entanto, o que realmente importa na reforma, são as respostas que vinculam a organização do conhecimento a aspectos maiores da transformação social e do poder. (p. 86)

Nessa perspectiva, rejeitando esse caráter redentor embutido nos discursos sobre a avaliação oficial, o autor nos possibilita compreender a reforma como "parte do processo de regulação social”. Nesses termos, entendemos a avaliação oficial também como um processo de regulação e intervenção social que envolve a atuação de vários sujeitos. Outra questão importante apontada por Popkewitz (1997) refere-se ao seu posicionamento em relação à regulação feita pela reforma educacional:

Demonstrando aqui minha preocupação com a qualidade instrumental da reforma, não estou considerando os padrões nem as regulamentações como males a serem evitados a qualquer custo. [...] A produção de regras e padrões através das práticas sociais fazem parte dos processos de regulamentação. (p. 145)

Essa postura, da qual compartilhamos, é fundamental para que não haja dúvidas de que consideramos o processo de regulação inerente às políticas educacionais. Popkewitz (1997) observa que as pesquisas sobre a reforma educacional giram em torno das análises da forma como as coisas funcionam e o tipo de intervenções que podem ser feitas para melhorá-las, ou seja, parte-se 
do princípio de que "os objetivos das relações sociais existentes são apropriados e somente precisam tornar-se mais eficientes” (p. 25).

Em relação ao processo de consolidação e divulgação dos dados produzidos pelas avaliações oficiais, destacamos a estatística como forte aliada. Lindblad e Popkewitz (2001), ao analisarem a utilização das estatísticas nos relatórios educacionais, demonstraram como elas, do ponto de vista desses relatórios, tornam o mundo inteligível e calculável, dando respaldo científico às intervenções políticas e sociais: "a estatística é uma modalidade chave para a produção de conhecimento necessário para governar" (p. 116). Logo, entendemos que a estatística não pode ser compreendida como algo neutro e norteador do progresso, uma vez que está condicionada aos fatores sócio-históricos que são construídos e não dados naturalmente.

Diante do exposto, consideramos que não basta apenas estudar a proposta de reforma em si, num âmbito essencialmente normativo. É necessário investigar também os diversos níveis sociais, dar voz aos professores para saber um pouco mais sobre o que eles pensam, priorizam e como se colocam em ação diante do processo de implementação da avaliação oficial, uma vez que esses são sujeitos que agem e/ou reagem no seu contexto profissional, podendo interferir nos rumos da reforma, uma vez que ela "depende, em parte, das ideologias específicas do individualismo e da prática profissional" (POPKEWITZ, 1997, p. 22).

Michel De Certeau (1994), ao discutir as práticas comuns da cultura ordinária dos sujeitos também comuns, e enfatizando as maneiras de fazer cotidianas, considera que os usuários ou consumidores culturais não são atônicos socialmente em relação à ordem vigente determinada pelas relações de poder; deve haver uma lógica dessas práticas, "uma maneira de pensar investida numa maneira de agir” (p. 42). Os conceitos mais significativos na sua obra e utilizados por nós são os de táticas e estratégias. Para o autor, estratégia é
[...] o cálculo (ou a manipulação) das relações de forças que se torna possível a partir do momento em que um sujeito de querer e poder (uma empresa, um exército, uma cidade, uma instituição científıca) pode ser isolado. A estratégia postula um lugar suscetível de ser circunscrito como algo próprio e ser a base de onde se podem gerir as relações com uma exterioridade. (CERTEAU, 1994, p. 99)

Diferentemente das estratégias, Certeau (1994) define a tática como

[...] a ação calculada que é determinada pela ausência de um próprio. Então, nenhuma delimitação de fora lhe fornece a condição de autonomia. A tática não tem por lugar senão o do outro. E por isso deve jogar com o terreno que lhe é imposto tal como o organiza a lei de uma força estranha. (p. 100)

Assim, tomamos as estratégias como relações exteriores à escola, desencadeadas nas relações de poder às quais as escolas estão subordinadas, como, por exemplo, a execução do Proalfa. As táticas, em contrapartida, são caracterizadas pelas relações internas à escola, que, diante das estratégias circunscritas pelos sujeitos de poder, cria maneiras diferenciadas de agir, jogando com o que é imposto, sendo elas imprevisíveis e realizadas de acordo com a ocasião.

\section{Resultados}

Apresentamos aqui um conjunto de elementos que nos possibilitam compreender, por meio do discurso das professoras alfabetizadoras, o impacto que o Proalfa tem causado em suas práticas em sala de aula.

\section{a) Principais características do Proalfa}

0 Proalfa é uma avaliação censitária para os alunos do $3^{\circ}$ ano (8 anos) e amostral para os do $2^{\circ}$ e $4^{\circ}$ anos. As questões do teste 
são formuladas de acordo com a matriz de referência, visando avaliar em que nível de proficiência o aluno está, sendo a maioria delas de múltipla escolha.

A matriz de referência do Proalfa constitui-se num conjunto de competências de leitura e escrita que delimitam o objeto de avaliação dos testes, especificado para o $2^{\circ}, 3^{\circ}$ e $4^{\circ}$ anos do Ensino Fundamental. (MINAS GERAIS, 2008, p. 13)

Ou seja, o erro ou acerto de um conjunto de questões indica, de acordo com a escala de proficiência, se o aluno está no nível de desempenho baixo, intermediário ou recomendável.

Em relação à participação, na rede estadual, é obrigatória, enquanto a rede municipal só participa se houver um termo de parceria da prefeitura com a SEE-MG. A rede particular não participa do Proalfa. De acordo com os dados documentais, percebemos que a participação dos alunos do $3^{\circ}$ ano no Proalfa aumentou de 2008 para 2009 tanto na rede estadual quanto na rede municipal, chegando a se avaliar $88,3 \%$ dos alunos da rede pública em 2009. Além disso, tanto em 2008 quanto em 2009, a participação dos alunos da rede estadual foi mais expressiva que na rede municipal. No entanto, a avaliação não abrange todos os alunos, como está expresso no discurso da SEE-MG, ou seja, destina-se a todos, mas não possui um alcance de $100 \%$ dos alunos.

Enquanto avaliação da alfabetização, o Proalfa não se restringe à aplicação de testes, uma vez que, paralelamente a essa ação, foram elaborados materiais didáticos que subsidiassem a prática dos professores. Assim, constatamos que a concepção de alfabetização e letramento presente nesses materiais (Cadernos I e II do Ceale, Cantalelê e Guia do professor alfabetizador) e na matriz de referência do Proalfa revela que as especificidades da alfabetização aparecem de forma objetiva e nas primeiras competências, sugerindo que o ensino do código é processo inicial nos primeiros anos de escolarização, seguido pelo conhecimento relacionado à compreensão, usos sociais e avaliação dos diversos portadores de textos, chegando então à competência de produção de texto, que requer tanto saberes relacionados às especificidades da alfabetização quanto do letramento, já que ambos são importantes e se complementam, e porque não concomitantes.

0 discurso político inerente ao Proalfa está centrado em um argumento fundamental: de posse dos resultados dessas avaliações, cada escola pode e deve traçar seu plano de intervenção, e cada professor poderá rever sua prática, e, assim, progressivamente, todos atingirão a tão almejada qualidade do ensino público. Vejamos então como as sete professoras convidadas a participar do grupo focal vivenciam essa realidade.

\section{b) 0 discurso das professoras sobre a alfabetização e o letramento no Proalfa}

Em relação às concepções de alfabetização e letramento expressas pelo grupo focal, podemos inferir que faz parte dos discursos a crença de que a alfabetização em si não é mais suficiente para a escola atual porque "não basta alfabetizar, tem que letrar”. E, ainda, afirmam que houve mudança na maneira de alfabetizar. De acordo com a professora Meire, citando um artigo que buscou na internet sobre o Proalfa, o analfabetismo é um problema de exclusão social, e a alfabetização se apresenta como um dilema de longa data:

E o nosso dilema, o nosso problema sempre
foi a alfabetização. E então agora, com essas
novas mudanças, com essas discussões, es-
tamos novamente estudando sobre os méto-
dos de alfabetização. Voltam os métodos de
alfabetização ou os métodos a utilizar, não
é isso?

Observamos que a mudança não se limita aos métodos de alfabetização. 0 discurso da professora Meire assume a voz dos representantes 
do Estado, destacando a questão dos gêneros textuais, sendo compreendida como um novo método para alfabetizar. Ou seja, com o Proalfa, os professores tiveram que passar do ensino baseado na "decoreba" para o ensino que "leve a pensar”. Em relação à alfabetização, elas remetem ao trabalho realizado "antigamente" como superado com o impulso do Proalfa, uma vez que agora se deve "alfabetizar letrando", por meio do trabalho com os diferentes gêneros textuais e do conhecimento das habilidades a serem alcançadas pelos alunos, sendo este um ganho proporcionado pelo Proalfa:

Porque de fato eu acho que deu um salto de qualidade na educação. E a partir do momento que a gente fala de alfabetizar daquele jeito que o aluno só decifra letra e fonema e nada mais, que só acha lá no texto a resposta exatamente naquele lugar ali, ali, e agora não, ele tem que entender o texto todo, ele tem que me falar daquele assunto, do que é que é... Quer dizer, isso é um avanço significativo, eu acho que a clientela melhorou nesse sentido! (professora Marta)

Parece que, para as professoras, a alfabetização e o letramento correspondem basicamente à seleção de atividades mais contextualizadas à realidade do aluno. Nesse sentido, apresentam, por vezes, uma visão utilitarista do ensino da leitura e da escrita: ensinar de determinada maneira porque é cobrado na prova ou porque é da vontade do governo, como aponta a professora Sílvia:

Ele [o governo] quer que a gente trabalhe com os diversos tipos de textos. Para quê? Para que o aluno, se ele se deparar com uma lista telefônica, ele sabe para que aquilo serve. Se ele se deparar com um cheque, ele também sabe. Por quê? 0 que é que acontece? Com esses textos que a gente trabalhava, assim, não é, que eram trabalhados, não tinha nada disso, era pergunta e resposta.
Essas afırmações sugerem a forma como os professores estão se apropriando do conceito de letramento que circula tanto por meio das avaliações oficiais como também nos processos de formação continuada, reduzindo o letramento à questão do trabalho com a diversidade textual, conforme analisa Souza (2010). Ao mesmo tempo, as professoras percebem, talvez de uma maneira radicalizada, um choque da política vigente com a proposta construtivista, já que, na lógica das metas estipuladas pelo governo, cai por terra o discurso de que cada um tem seu tempo de aprendizagem. De acordo com a professora Marta,

[...] o tempo de cada um não importa porque se no ano passado [a proficiência] foi 600 eu não posso mais aceitar 600 dos que estão vindo ainda! Eu já tenho que esperar que sejam 700.

Outra preocupação se volta para o início da alfabetização cada vez mais cedo, aos 6 anos de idade:

Agora a grande preocupação é ter que estar alfabetizado, e não é só alfabetizado, é letrado, não é? Até os 8 anos! Essa que está sendo a maior pressão em cima da escola, em cima dos professores das séries iniciais. Porque não só no $3^{\circ}$ ano, mas o $1^{\circ} \mathrm{e} 2^{\circ}$ agora também já estão sentindo a pressão, porque se eles não fizerem a parte deles o aluno vai chegar no $3^{\circ}$ sem as competências e as capacidades mínimas... (Marta)

Ela ainda aponta o fato de o governo de Minas Gerais ter antecipado a meta brasileira (para o ano de 2022) de toda criança estar alfabetizada até os 8 anos de idade para 2010, como uma estratégia política, antes de mais nada:

Tem que fazer ler antes... Então eu penso que tem, que tem coisa por trás tem, não? Claro! Investimento político acima de tudo, isso virou uma bandeira que está dando a ele um status dentro, não é, do panorama nacional. (Marta) 
Esse trecho demonstra que a professora reconhece os significados político-econômicos que as altas taxas de alfabetização de uma população trazem aos governos e vê com desconfiança o fato de o governo mineiro ter formulado uma meta com prazo bem mais curto que a meta nacional.

Em sintese, as professoras assumem como um ponto positivo o discurso sobre alfabetização e letramento que está presente em torno da avaliação, mesmo reconhecendo que este circula muito antes de a avaliação ser implementada. No entanto, as colocações feitas pelas professoras sugerem que, diferente da concepção de alfabetização e letramento do Proalfa (que prioriza a primeira, mas também considerando a segunda), há uma atribuição de importância ao letramento, uma vez que o ensino do código quase não foi abordado enquanto o termo letramento conferia ao discurso das professoras status de "nova metodologia". Ou seja, conforme já apontou Soares (2004), após a chegada do conceito de letramento no Brasil, há uma tendência de se atribuir mais valor ao letramento que à alfabetização. Mas ambos são igualmente indispensáveis e não podem ser tratados de forma dicotômica.

\section{c) As estratégias de governo para o Proalfa}

Foi interessante notar como as professoras situaram historicamente as políticas educacionais implantadas no Estado de Minas Gerais. Conforme afirmou a professora Virgínia, o controle do Estado sobre o que se faz na escola sempre existiu, independente da metodologia e das concepções de ensino dos professores:

Porque o governo, de uma certa maneira, já fazia avaliações externas ali e o Proalfa não é novidade. E, a supervisora com quem eu trabalho há muitos anos, ela sempre fala: é o velho voltando o tempo todo com uma roupagem nova. Então, antigamente, ela falava, quando ela dava aula, as provas que eram aplicadas bimestrais nos alunos, elas vinham padronizadas, elas vinham em envelopes lacrados. Isso era uma maneira de controlar o que o professor passava para o aluno, o que ele ensinava. Era uma decoreba? Que fosse... Era sem questionamento, sem o equipamento (???), era. Mas eles já faziam uma avaliação e um controle externo...

0 seu discurso assume aqui a voz da escola, fala do ponto de vista de quem trabalha na educação e está subordinado à política do Estado. Já a professora Meire define o Proalfa como um diagnóstico destinado a ajudar os professores, reafirmando a voz oficial da SEE. Esse seu posicionamento foi reiterado durante todo o encontro, e supomos que é consequência da posição que ocupa na escola. Ela possui dois cargos: um de professora regente e outro de especialista da educação e, no grupo focal, assumiu predominantemente o ponto de vista de quem possui a função de supervisionar os professores na escola. Isso evidencia que os discursos são produzidos sob determinadas condições, não podendo ser considerados neutros ou transparentes. Os sujeitos falam ocupando um determinado lugar social e, nesse processo, evidenciam a sua "apreciação valorativa” indicando a posição ideológica assumida no processo de interlocução (BAKHTIN, 1995). Vejamos uma situação descrita por ela:

No ano passado, quando eu fui nos congressos de Belo Horizonte e teve lá aquele congresso sobre alfabetização, volta de novo, quais os métodos? Aí a... Secretária [...] falou que o Proalfa, um dos objetivos do Proalfa, é o diagnóstico mesmo, onde os professores estão precisando de ajuda; a escola está precisando de ajuda... e, realmente, o Proalfa faz o diagnóstico disso tudo, não é?

A professora Meire enfatizou o objetivo desta avaliação de diagnosticar a aprendizagem do aluno; a professora Virgínia discordou e disse que o objetivo era exercer o controle. Observamos aqui uma tensão entre o discurso de autoridade materializado na 
voz de Meire ao assumir a voz da avaliação oficial e um discurso internamente persuasivo (BAKHTIN, 1995) materializado na voz de Virgínia, que se contrapõe reafirmando o controle do Estado em suas práticas pedagógicas. Ficou claro que os especialistas possuem mais acesso às informações sobre os projetos da SEE, o que conferiu a ela mais conhecimento dos mesmos, participação na elaboração, por vezes, e por isso dispõem de argumentos em defesa dos projetos da SEE. Esse aspecto é importante porque demonstra que muitos questionamentos feitos pelas professoras se dão pela falta de conhecimento da própria estrutura da SEE e do funcionamento dos seus projetos.

Nesse cenário, os professores parecem buscar explicações para aquilo que é imposto sem maiores informações e discussões. Esse quadro de trajetória da política pública nos dá indícios de que possíveis dificuldades de acesso à informação sobre a política pública provocam nos professores uma sensação de exclusão dos processos, ficando perdidos e até resistentes à sua função de colocar em prática um projeto que pouco conhecem.

Trazendo resultados da pesquisa sobre o impacto do Simave ${ }^{1}$ em duas escolas no município de Uberlândia, realizada por Silva (2007), destacamos, em suas análises, algumas considerações que dialogam com nossa pesquisa, tais como: o sentimento de exclusão produzido nos professores, "primeiramente por não terem sido consultados sobre a elaboração do projeto e as questões das provas, e, ainda, por não poderem participar do processo de aplicação" (p. 245). Para a autora, esse fato se deve também por conta dos professores não compreenderem "a razão pela qual a escola estava sendo avaliada, logo, mais uma vez há indícios de falha na comunicação entre os gestores da educação e os professores" (p. 247). Devemos considerar que o contexto investigado por Silva precede a

1. Sistema Mineiro de Avaliação implantação do Proalfa, mas trata do Simave e chegou a algumas considerações análogas às que encontramos investigando o Proalfa.

Em relação à divulgação dos resultados, de acordo com as professoras, após a aplicação do Proalfa, são enviados boletins pedagógicos às escolas, com seus resultados, a serem analisados:

Aí a diretora chamou os professores e fez uma reunião com o grupo das séries iniciais. Com as professoras de um modo geral. Aí faz um gráfico e explica, tal. E vai falando: “mas por que é que veio esse resultado?". Aí compara com o do ano anterior. Caiu, não caiu, o que aconteceu? Aí eu senti, eu fiquei com pena da minha colega, coitada, ela, ela suava para explicar, para tentar explicar. (Lais)

Nesse sentido, as discussões no grupo indicaram que a cobrança se dá num efeito dominó:

Então, assim, se o acordo de metas que o secretário fez é alcançar a meta "tal", ela, como superiora, cobra de todas as superintendentes, e as superintendentes cobram dos diretores, os diretores cobram dos professores e nós cobramos dos alunos. (Virgínia)

Esse discurso evidencia as diferentes hierarquias que compõem o processo e a prática da avaliação ofıcial, bem como as relações de poder presentes nas interações dos sujeitos envolvidos durante a elaboração e implementação da política pública. Reflete os efeitos de poder e está "intrincadamente limitado pelas regras, padrões e estilos de raciocínio, de acordo com os quais os indivíduos falam, pensam e agem na produção do seu mundo cotidiano. 0 poder é relacional e regional" (POPKEWITZ, 1997, p. 238).

Mas, para a professora Laís, mais do que diagnosticar e avaliar a aprendizagem dos alunos, o Proalfa avalia o professor: 
Eu concluí o seguinte: quando vem o resultado, eu acho que esse diagnóstico fica como pano de fundo porque na verdade eu acho que o Proalfa, ele vem avaliar o professor; isso, digo porque eu senti, as minhas colegas, a pressão que elas passaram quando veio o resultado da minha escola. Aí fez aquela reunião... “Ah, mas não atingiu isso... por quê?”.

Soma-se a isso o fato de os resultados virem cada vez mais específicos, outra estratégia de governo para indicar onde estão os bons resultados e onde estão os resultados que necessitam de intervenção. Mas essa prática tem outras consequências no interior e entre as escolas. A exposição nominal dos indivíduos envolvidos na avaliação pode tanto conferir a eles status pelo bom resultado como expô-los de maneira negativa pelo mau resultado:

E você falava de um modo geral: tinha o resultado da superintendência, tinha o resultado do município e tinha o resultado do Estado. Depois, isso evoluiu para a questão da escola mais especificamente. E agora é do aluno. Vem na folhinha atrás com o resultado do aluno.

0 trecho acima indica que as professoras estão acompanhando a forma de divulgação dos resultados cada vez mais individualizada e atribuem a esse processo grande parte da carga negativa à qual estão sujeitas. Silva (2007) também aponta para essa direção: "apreendemos dados que confirmam a sensação de vigilância, bem como o sentimento de insatisfação por estarem sendo avaliados" (p. 246).

Nota-se que os professores, desde a implantação do Simave, se sentem vigiados pela avaliação, fator provocado também pelo fato de a regulação ser inerente à política educacional. No segundo encontro, elas voltaram a esse assunto, conforme o trecho abaixo, apontando outros desdobramentos:

No ano passado, veio num caderninho, o nome da professora e nome dos alunos dela com a nota que cada um tirou, não é? Eu acho que isso também pesa muito! Aí fica assim a fulana, na sala da fulana teve nota boa, na sala da sicrana não teve nota boa, não é? Fica aquela coisa, de cunho pessoal, inclusive, não é? [...] Porque aí, inclusive, vem outro problema: "ah não, eu quero o aluno, meu filho, seja da professora ciclana porque na sala dela é que tem nota boa e não na sala da outra", não é, Virgínia? (Marta)

Ou seja, não é apenas o fato de dentro da escola estar se produzindo o ranqueamento de professores e alunos que traz incômodo às professoras. Essas informações extrapolam os muros da escola, chegando aos pais dos alunos, que, por sua vez, tendem a assumir a dimensão de controle da avaliação e passam a categorizar e escolher as professoras sob o critério dos resultados da avaliação oficial. Tudo isso, sem dúvida, motiva um clima de competição exagerada, impulsionada pelo desempenho individual em uma avaliação que se propõe a conhecer a situação da escola como um todo. Além do mais, como apontam as professoras, não será uma lista de classificação que irá resolver os problemas pedagógicos da escola. Conforme questiona Gatti (2007):

Pergunta-se: Que contribuições trazem de fato, por quê, para quê e para quem? É um processo alavancador para escolas, professores, alunos, gestores, ou será um processo para comparações humilhantes ou descabidas? É um processo que alimenta a cooperação e busca de soluções coletivas ou, serve apenas para alimentar competição e concorrência exacerbadas? (p. 57)

Essas são perguntas realmente pertinentes, e as respostas precisam ser buscadas por meio de pesquisas com tal objetivo. Mas uma consequência dessa concorrência exacerbada foi identificada pela professora Carmem: "vai acontecer que não vai ter mais 
professores alfabetizadores..." A pressão começa já no momento da contratação do professor, e muitos professores mais experientes estão desistindo de lecionar nos anos iniciais.

Gatti (2007), tratando das avaliações oficiais em geral, faz referência à forma de divulgação dos resultados:

Mas, também há um fator relativo à divulgação e disseminação dos resultados das avaliações realizadas: a divulgação via imprensa é estrepitosa. Limita-se a comparações duvidosas, e dura um dia - cai no esquecimento, a disseminação nas redes não é planejada e enfatizada, e a forma com que se apresentam os resultados, de um lado não são de leitura fácil, e de outro, não contribui com elementos claros quanto aos aspectos de seqüência didática e aspectos sócio-psico-pedagógicos relativos aos processos de ensino de crianças e jovens. (p. 54)

Para a autora, a divulgação é feita com muita pompa, barulho, e em seguida é esquecida. Ela aponta ainda para outra questão: da inteligibilidade dos dados, que são ainda de difícil interpretação. Silva (2007) também abordou a questão da interpretação dos dados:

Percebemos que, no discurso oficial, a intenção é a praticidade, a interação e a efetividade no diálogo com as escolas para culminar em intervenções direcionadas aos problemas detectados. Mas percebemos também que na prática, pela própria natureza do instrumento e pela pouca familiaridade que os educadores têm com a área de estatística, há uma barreira para a interpretação e compreensão clara dos dados expostos. (p. 248)

Sobre os materiais distribuídos pela SEE, como Cadernos do Ceale, Guia do professor alfabetizador e Cantalelê, houve consenso entre as professoras no que se refere à sua "excelente qualidade", ainda que elas não tenham participado do processo de elaboração:
Isso veio de lá [olhou para cima], de cabeças pensantes, de gente que estudou para se desenvolver essas habilidades, que viu que essas, viram que essas habilidades seriam importantes nesse momento. E o governo veio e abraçou essa causa porque não é bobo nem nada, não é gente? (Marta)

Fica expressa, nessa fala, a relação de poder entre universidade e governo na legitimação de políticas públicas, demonstrando que essas articulações conferem credibilidade ao discurso lançado pelo governo. Entretanto, os materiais encomendados pela SEE parecem não ser apropriados pelos professores da forma que 0 governo espera. Tanto é que, num primeiro momento, as professoras nem se lembravam deles; elas veem esses materiais como de boa qualidade, mas não parecem segui-los diariamente; utilizam-nos como suporte e sempre empregam o termo: "tem que correr atrás; tem que buscar". Dessa forma, observamos uma tensão no processo de apropriação da política pública, na medida em que os professores a tomam como uma referência, mas do ponto de vista da lógica de suas práticas, e não simplesmente como reprodução do que é prescrito, colocando-se como sujeitos que agem na construção do cotidiano escolar.

Ainda em relação a esses materiais, as professoras ressaltam mais uma variável que atravessa a implementação da política pública, ligada à falta de condições adequadas de acesso aos materiais. Elas questionaram a demora na entrega, como relatou Virgínia:

0 Guia do alfabetizador, ele chegou às mãos dos professores no segundo semestre. E, inclusive, veio o primeiro bimestre, que chegou no terceiro bimestre, o segundo e o terceiro. 0 quarto ainda não foi publicado e não está nas mãos da gente. Nem na internet...

Nesse momento, a professora Meire, reassumindo a voz do discurso oficial, explicou o porquê da demora da entrega dos materiais. Segundo ela, no mês de abril, os supervisores 
das escolas e inspetores da SRE foram convocados para analisar o Guia do professor alfabetizador em Belo Horizonte. "Então eu achei muito interessante porque antigamente vinha tudo pronto para a escola. Nós não éramos convidados para nada!" (Meire). E devido a todo esse processo de análise, houve o atraso na entrega do Guia. Torna-se notório, por essas falas, que, quando o profissional é inserido na produção de uma política pública, fica muito mais fácil de ela ser legitimada por ele. Isso porque ele se sente parte do processo, e não apenas um instrumento.

Para o caso das escolas que não vão bem nas avaliações, existe um outro procedimento, os projetos cujos objetivos são corrigir aquele desvio. Elas são denominadas "escolas estratégicas” e são visitadas por pedagogos da SEE-MG. Na discussão sobre elas, tivemos duas posições distintas no grupo. A professora Meire concorda com a estratégia do governo e entende que essas visitas visam "auxiliar, ver o que o professor, a escola está precisando de ajuda”, enquanto a professora Marta acha que, para a SEE, o baixo resultado demonstra que "eles estão entendendo que a escola não está fazendo”, que os professores não estão trabalhando direito.

Enfim, para as professoras, tal prática, mesmo que tenha o objetivo de ajudar as escolas, pode criar um certo estigma, e elas demonstraram repulsa à possibilidade de fazer parte do corpo docente de uma escola estratégica. Nesse sentido, o caráter normativo da reforma dentro das relações de poder deve ser analisado considerando o fato de que provoca mudanças e posicionamentos esperados e não esperados, já que é aqui considerada como "um objeto das relações sociais", rejeitando a visão de reforma "como produtora de verdade e progressista (POPKEWITZ, 1997, p. 259).

\section{d) Táticas das professoras alfabetizadoras}

Os discursos analisados sugerem que as professoras apoiam o Proalfa, mas sem deixar de questionar os aspectos dos quais discordam, como, por exemplo, a forma como o teste é aplicado e a pressão que é feita sobre os professores. Por isso, colocam em prática táticas de ação tanto colaborativas, ou seja, que legitimam os objetivos do Proalfa, quanto de resistência, ou seja, de reação, adaptação ou burla daquilo com que não concordam. Desse modo, elas não se mostram alheias às propostas do Proalfa. As professoras afirmam que, diante do Proalfa e das exigências que o acompanham, tiveram que "entrar no molde". Enumeram então as ações que desencadeiam com o objetivo de se adequar às novas exigências, configurando táticas de legitimação.

Ver a clientela, conhecer os alunos, é uma das principais táticas apontadas pelas professoras. É interessante observar que a terminologia utilizada remete à perspectiva da lógica da escola associada à lógica de mercado no uso do termo "clientela". Para além disso, diante de turmas com dificuldade de aprendizagem e com a eminência da avaliação oficial, tomamos como exemplo a professora Inês, que contou como agiu diante dessa situação, buscando conhecer os alunos:

\begin{abstract}
Através daquilo que eles estavam apresentando eu fui! [...] Eu fiquei conhecendo primeiro cada aluno, problema, situação de cada um. É o que nós hoje estamos, é, vivendo. As dificuldades de cada um! Aí eu fui procurar saber a história de cada um para saber aonde que eu ia tocar. (Inês)
\end{abstract}

Estudar, criar atividades para se atingir aquela competência, pesquisar na internet, revela o esforço das professoras em mudar a metodologia de trabalho a partir dos indicadores do Proalfa. Conforme disse a professora Marta, "a gente pega os papéis no Sales" ${ }^{2}$. É recorrente a fala de que cada escola ou professor tem que "se virar" nesse sentido de buscar alternativas para se adequar às exigências, mesmo que as condições oferecidas não sejam as mais favoráveis.

2. Rede de supermercados com lojas em São João Del-Rei e região. 
As professoras parecem estar o tempo todo pensando engenhosamente em que tática utilizar em determinada situação. Diante da falha da SEE na entrega de materiais, elas lançam mão de medidas paliativas para minimizar o problema, como, por exemplo, pegar panfletos em supermercados e levar para a sala de aula a fim de permitir o contato dos alunos e o ensino com base na diversidade textual, o que representa a forma como elas entendem a proposta de alfabetização e letramento do Proalfa. Conforme ilustra a fala de Meire: "Cada escola teve que se virar! Se virar como? Ou xerocar, ou, igual fizeram lá na escola I, passa no mimeógrafo, não é?”.

Outra tática muito utilizada é aplicar testes semelhantes ao Proalfa, conforme apontou a professora Sílvia: "E outra coisa, não sei se elas já perceberam, porque agora, como está sendo, a gente tem que trabalhar isso direto, não é? Então a gente dá vários destes testes na sala de aula, esses pequenos textos para marcar alternativa”.

A professora Inês também afirmou ter adotado essa tática ao dizer que, no momento de elaboração das provas, "você tem que ter mais malícia na hora de colocar, entendeu? Porque tem que levar ele a pensar. Isso eu gostei e eu imitei".

Analisar os gráficos dos resultados e priorizar as habilidades que o aluno não atingiu é outra tática das professoras para buscar garantir um melhor desempenho dos alunos em avaliações futuras: "Quando eu vi o gráfico da minha turma, aí eu vi que não venceu. Qual habilidade? Essa da inferência" (professora Meire). "Assim como o governo, a gente vai em cima daquilo que não venceu” (Marta).

Nesse sentido, Silva (2007) problematiza uma tendência semelhante:

As discussões realizadas após a divulgação dos resultados têm sido superficiais e incipientes, além de pontuais. De acordo com os interlocutores, os resultados são discutidos brevemente em reuniões na escola. A ênfase recai sobre as proficiências - adquiridas e não adquiridas discriminadas nos gráficos. (p. 250)
Ou seja, as análises realizadas pelas escolas parecem se concentrar na identificação, nos gráficos de proficiência, das habilidades alcançadas e não alcançadas, podendo simplificar demasiadamente a intervenção pedagógica, adaptando o planejamento àqueles conteúdos em defasagem apenas.

$\mathrm{E}$, nesse contexto, identificamos, além das táticas de legitimação, as táticas de resistência. Diante da possibilidade de não alcançar os resultados, são colocadas em prática ações pedagógicas que parecem ser justificáveis diante da necessidade de alcance de resultados para se evitar possíveis punições.

As atividades de treinamento dos alunos são recorrentes, como se pode observar no trecho a seguir: "Olha gente, vocês vão estudar isso aqui hoje porque isso vai cair na prova que vocês vão fazer! "Está chegando a um ponto: treinamento!” (Virginia).

0 acesso aos testes no dia da aplicação, mesmo não sendo autorizado pela coordenadoria central e regional da prova, é um dado importante que evidencia a transgressão da norma como uma forma de resistir ao Proalfa: “é, porque fala lá que não pode tirar xérox, fala lá que não pode olhar, mas todo mundo olha! (...) Eu fico curiosa para pegar uma prova" (Inês). Essa proibição incita a curiosidade das professoras. E, quando não há o acesso no momento da aplicação, elas procuram ver as questões que vêm de exemplo nos boletins pedagógicos:

\footnotetext{
"Eu gosto de ver as questões quando vem caderninho, eu gosto de estudar o caderninho para ver que tipo, como é que aquela questão foi elaborada, isso para mim é bom porque me ajuda na prática” (Marta).
}

Outra forma de resistência é alterar a forma de aplicação do teste, quando o aplicador passa a interferir no processo. As professoras dizem, de maneira geral, que sabem de casos de aplicadores que "direcionam" a aplicação do 
teste, o que não é permitido pela coordenação do Proalfa, e demonstram se sentir em desvantagem diante dessa prática:

Têm escolas que o aplicador lê literalmente todos, todos os enunciados. E aí lê. E é aquilo: "todo mundo já respondeu a primeira questão? Levante a mão!”. Passa de carteira em carteira e confere: "você ainda não respondeu!". Espera; “agora, vamos para a segunda”. É, realmente é dirigido. Quando é assim, pode ter certeza que o resultado é bem melhor. (Virgínia)

A procura de explicações e culpados para o que não deu certo foi outra forma de resistência identificada na fala das professoras. Elas dispõem de um conjunto de argumentos cuja finalidade principal é aliviar o nível de responsabilidade pelo fracasso dos alunos no Proalfa a elas imputado tanto pela sociedade quanto por elas mesmas. Vejamos a síntese desses argumentos:

0 primeiro deles é o fato de ser "cruel o professor ser avaliado pelo resultado do aluno":

Sílvia: Mas, gente, eu vou fazer uma pergunta, não sei se vocês vão concordar comigo: vocês acham que o fracasso da escola só depende de nós professores?

Virgínia: É, eu já perguntei isso 10 mil vezes... (risos)

Sílvia: Então, mas eu acho, assim, que o fracasso da escola não é culpa só do professor, não, porque é muito fácil a gente falar, no papel, igual eles mandam, a gente tem que fazer isso e a gente faz. Mas a gente tem aluno que não está querendo nada!

$\mathrm{Na}$ visão das professoras, o principal impacto causado pelo Proalfa foi a mudança de metodologia de ensino nas aulas, principalmente em relação à elaboração das avaliações internas em consonância com as avaliações oficiais.

Essa avaliação veio remexer com o que a gente tinha como certo, com aquilo que a gente acreditava. Até mesmo ao a gente elaborar uma avaliação nossa... (Marta)

Mas a maioria é tradicionalista, sim, com feijão com arroz, gente, não põe uma saladinha ali. Então eu acho assim, eu acho que o lado bom do Proalfa que eu percebi é que está obrigando... (Laís)

E lá em Belo Horizonte eles falaram: ou o professor muda ou ele sai, porque não tem espaço mais para aquele professor que trabalha na mesmice, pegando o plano de aula de todo ano, não tem! (Meire)

Após criticar a metodologia de aplicação do Proalfa por não permitir a leitura das questões para os alunos, a professora Sílvia afirmou: "a gente tem que parar de ler as nossas provas para o aluno, para que eles se acostumem". Observamos aqui mais um impacto do Proalfa na prática docente, que se refere à metodologia das avaliações: se antes os professores liam as questões para seus alunos em momentos de avaliação formal, com a implantação do Proalfa constatamos no grupo focal que as professoras alteram a metodologia de aplicação da avaliação interna, evitando a leitura das provas em momentos de avaliação, seguindo a metodologia utilizada na avaliação oficial.

Outro ponto que merece destaque é a crença das professoras de que o professor só muda se for obrigado: "porque antes fala-se, mas a gente não pratica, praticava?" (Meire); "Eu penso que ele [o governo], ele tem feito realmente, ele tem de certa maneira nos cercado, para ver se a coisa anda.” (Marta)

A expressão "para ver se a coisa anda" traduz o pensamento da professora de que, se não houver cobrança por parte do governo, as ações nas escolas diante dos alunos com dificuldade de aprendizagem demorariam mais para acontecer.

Enfim, as professoras atribuem ao Proalfa a obrigatoriedade da mudança de metodologia das aulas e das avaliações internas, o 
maior direcionamento da atenção aos alunos com dificuldade de aprendizagem, dificultando posições comodistas por parte dos docentes e da própria escola. Por outro lado, a grande carga de responsabilização que os professores dos anos iniciais vêm sofrendo, que tem causado uma resistência em lecionar para turmas de alfabetização, é conferida ao mesmo sistema de avaliação.

\section{Consideraçōes finais}

Diante das estratégias de governo, os professores lançam mão de táticas de consumo daquilo que é imposto às escolas como algo a ser seguido. As táticas variam de acordo com a legitimação conferida aos objetivos dessa política, ou seja, para que as professoras ajam de forma a corroborar o Proalfa, primeiro, elas têm que estar convencidas de que dará certo. Nos aspectos em que esse convencimento não se concretiza, elas colocam em prática as táticas de resistência, principalmente através de discursos marcados por elementos explicativos daquilo que não está sendo alcançado, bem como suas possiveis causas. É importante realçar que, conforme aponta de Certeau (1994), essas táticas são pensadas e colocadas em prática conforme a ocasião e de maneira individual, jogando com as estratégias do governo.

É fato que os objetivos das avaliações oficiais precisam, cada vez mais, ser apropriados pela classe docente e que a interpretação dos seus resultados deve se tornar mais acessível, em consonância com os objetivos das avaliações internas, que nesse contexto não perdem seu espaço. Nessa direção, não basta que sejam oferecidos materiais de apoio, realizadas reuniões pedagógicas ou veiculadas propagandas etc. Os profissionais da educação precisam se sentir inseridos nessa empreitada e estar abertos aos potenciais que os dados das avaliações oficiais são dotados.
As professoras demonstraram muita curiosidade em relação ao teor da prova. Talvez essa proibição por parte da SEE-MG contribua mais para o aumento da ansiedade dos professores e o sentimento de exclusão do processo de avaliação do que para a manutenção do sigilo das questões.

0 fato de as professoras priorizarem, em sua fala, o letramento e omitirem a questão da alfabetização permite questionar como os cadernos do Ceale são apropriados pelas alfabetizadoras, uma vez que neles já estão colocadas as discussões mais recentes sobre letramento, conforme aponta Soares (2004). Como está sendo feita a capacitação dos professores? Por que eles não demonstram problematizar a questão dessa maneira?

Por outro lado, foi interessante notar que, para as professoras, a mudança foi positiva e só se deu devido ao caráter de obrigatoriedade ao qual foram sujeitas. Tal fato suscita a questão da autonomia docente: como elas lidam com a questão da autonomia? Sem a presença da pressão, a mudança não aconteceria? 0 fracasso escolar dos alunos em si mesmo já não incomodava as professoras? Talvez esse fato seja explicado também pelo poder de persuasão da avaliação. Não que antes o fracasso não incomodasse as professoras, mas talvez não fosse tão explicitado; os resultados dos alunos não eram expostos na mídia, nem havia um controle externo organizado em torno deles.

Em relação à prática de ranqueamento entre as escolas e professoras e à resistência das mais experientes em lecionar para as turmas de alfabetização, precisamos ponderar se possuem um caráter pontual, ocorrendo apenas em algumas escolas, ou se é geral na rede. De qualquer forma, esse indício é preocupante, uma vez que precisamos de investimentos que contribuam para a valorização da profissão docente e não para uma debandada de professoras alfabetizadoras em qualquer escala que seja. 


\section{Referências}

BARTON, David; HAMILTON, Mary; IVANIC, Roz. Situated literacies: reading and writing in context. Nova York: Routledge, 2000. BAKHTIN, Mikhail. Marxismo e filosofia da linguagem. São Paulo: Hucitec, 1995 [1929].

CERTEAU, Michel D. A invenção do cotidiano: artes de fazer. Petrópolis: Vozes, 1994.

CUNHA, Maria Isabel da (Org.). Formatos avaliativos e concepção de docência. Campinas: Autores Associados, 2005.

GATTI, Bernadete A. Avaliação e qualidade da educação. Cadernos ANPAE, v. 1, n. 4, p. 53- 62, 2007.

Grupo focal na pesquisa em ciências sociais e humanas. Brasília: Líber Livro, 2005.

HEATH, Shirley Bricwe. Ways with words. Cambridge: CUP, 1983.

LINDBLAD, Sverker; POPKEWITZ, Tom S. Estatísticas educacionais como um sistema de razão relações entre governo da educação inclusão e exclusão sociais. Educação e Sociedade, Campinas, v. 22, n. 75, p. 11-148, ago. 2001.

MINAS GERAIS. Boletim de resultados Proalfa 2008: SRE de São João del-Rei. Belo Horizonte, 2008.

POPKEWITZ, Tom S. Reforma educacional: uma política sociológica (poder e conhecimento em educação). Porto Alegre: Artes Médicas, 1997.

SILVA, Maria J. Almeida. 0 sistema mineiro de avaliação da educação pública: impactos na escola fundamental de Uberlândia. REICE - Revista Electrónica Iberoamericana sobre Calidad, Eficacia y Cambio en Educación, v. 5, n. 2, p. 241-253, 2007.

SOARES, Magda. Letramento e alfabetização: as muitas facetas. Revista Brasileira de Educação, Campinas, n. 25, p. 5-17, jan./ abr. 2004.

SOUZA, Elisabeth Gonçalves. A polifonia na construção do discurso docente acerca das concepções de alfabetização. São João Del-Rei, 2010, 194p. Dissertação de mestrado em processos educativos e práticas escolares - Universidade Federal de São João del Rei, SJDR.

STREET, Brian V. Literacy in theory and practice. Cambridge: Cambridge University Press, 1984.

Recebido em: 08.04.2010

Aprovado em: 12.09.2010

Gisele Francisca da Silva Carvalho é mestre em Educação pela Universidade Federal de São João Del-Rei e analista educacional da Superintendência Regional de Ensino de São João Del-Rei.

Maria do Socorro Alencar Nunes Macedo é professora do programa de pós-graduação em Educação, coordenadora do grupo de pesquisa em alfabetização e letramento (GPEALE) da Universidade Federal de São João Del-Rei, pós-doutora em Educação pelo King's College, University of London. E-mail: socorronunes@ufsj.edu.br 